\title{
APLIKASI SISTEM PAKAR PENDAMPING PERAWATAN KESEHATAN PRIBADI BERBASIS ANDROID “CO-PAD” (COMPANION PAD)
}

\author{
Puji Andrianto \\ Program Studi Informatika Universitas Muhammadiyah Surakrta (UMS) \\ Surakarta, Indonesia Puji.informatika14@gmail.com \\ Nurgiyatna \\ Program Studi Informatika Universitas Muhammadiyah Surakrta (UMS) \\ Surakarta, Indonesia Nurgiyatna@ums.ac.id
}

\begin{abstract}
Kebanyakan orang tidak mengetahui gejala-gejala penyakit yang ada sehingga tidak memperhatikan hal tersebut, dan akan pergi ke dokter bila sudah terasa sangat sangat sakit dan mengganggu aktivitas. Padahal dengan mengetahui gejala penyakitnya, mereka dapat mencegah agar sakitnya tidak menjadi lebih parah. Sistem ini dibuat guna membantu masyarakat mendeteksi gejala-gejala penyakit yang mereka rasakan agar penyakit dapat dicegah sebelum menjadi lebih parah. Sistem dibuat berbasis android agar dapat diakses dengan mudah oleh seluruh masyarakat. Penambahan fitur masukan suara (voice recognition) bertujuan untuk lebih memudahkan masyarakat menggunakan sistem ini. Sistem akan menarik kesimpulan dengan metode decision tree berdasarkan aturan/rule yang tersedia. Sistem juga akan memberikan informasi mendetail tentang keterangan, gejala dan penanganan awal penyakit-penyakit tertentu. Sistem dibuat dengan menggunakan aplikasi android studio dengan bahasa pemrograman java. Hasil pengujian blackbox menunjukkan bahwa sistem berjalan dengan baik, fitur masukan suara mampu menerjemahkan suara menjadi teks secara akurat. Pengujian validasi mennjukkan bahwa diagnosa sistem sudah sesuai dengan hasil diagnosa pakar. Aplikasi dapat diterima dengan baik, ditunjukkan dengan hasil pengujian user acceptance menunjukkan hasil 82,6\%. Fitur masukan suara sangat membantu aplikasi menjadi lebih mudah dipahami..
\end{abstract}

Kata Kunci: android, voice recognition, decision tree, android studio, java, blackbox, user acceptance, diagnosa.)

\section{PENDAHULUAN}

Kesehatan merupakan hal yang sangat penting bagi manusia. Namun ironisnya banyak penyakit yang sulit untuk didiagnosa oleh masyarakat. Ketidaktahuan ini sangat disayangkan, masyarakat cenderung tidak memperhatikan gejala-gejala penyakit yang masih ringan seperti, sakit kepala, nyeri sendi atau batuk. Masyarakat tidak memperhatikan hal tersebut karena hal itu tidak begitu mengganggu aktivitas dan juga anggapan bahwa gangguan tersebut akan hilang dengan sendirinya. Gejala penyakit tersebut terkadang merupakan gejala penyakit tertentu yang lebih parah daripada yang diperkirakan. Padahal dengan didiagnosa lebih awal, gejala-gejala penyakit tersebut dapat ditangani sebelum mencapai tahap kronis/stadium tinggi. Sampai gejala tersebut mulai mengganggu masyarakat secara fisik yang teramat sangat dan mengganggu aktivitasnya barulah memeriksakan keluhan-keluhannya tersebut ke dokter.

Oleh karena itu perlu adanya alat bantu untuk diagnosa penyakit dari gejalagejala/keluhan-keluhan yang dirasakan oleh masyarakat. Sehingga masyarakat dapat mengetahui bagaimana cara menangani gejalagejala/keluhan-keluhan yang dirasakan dan dapat melakukannya sendiri apabila masih dalam level rendah atau sedang. Adanya alat 
bantu diagnosa tersebut juga dapat mengurangi kecenderungan masyarakat untuk langsung pergi berkonsultasi kedokter hanya untuk menangani gejala penyakit ringan yang dapat dilakukan sendiri.

Supriyono (2015) dalam penelitiannya "Sistem Pakar Berbasis Logika Kabur untuk Penentuan Penerima Beasiswa" menuturkan bahwa sistem pakar adalah sebuah program komputasi dalam komputer untuk menyelesaikan permasalahan yang kompleks dengan cara meniru cara berpikir manusia yang pakar dibidang tersebut. Disampaikan juga oleh Oluwafemi (2015) bahwa sistem pakar pada perawatan kesehatan manajemen rumah sakit menjadi salah satu aplikasi terbaik untuk menurunkan diagnosis yang berarti bagi tantangan kesehatan manusia.

Sistem pakar adalah alat bantu yang tepat untuk masalah penanganan kesehatan diatas. Sistem pakar telah dikembangkan dalam berbagai bidang. Pada bidang kesehatan Bria dan Takung (2015) telah melakukan penelitian membuat sistem pakar untuk mendiagnosa penyakit Tuberculosis dan Demam Berdarah. Hasil penelitian menunjukkan bahwa hasil pengujian perhitungan berdasarkan sistem pakar dengan perhitungan manual memiliki nilai yang sama.

Jenis masukan untuk sebuah sistem sangatlah bermacam-macam seperti, mouse, keyboard, touchscreen, suara dll. Masukan yang berupa fisik terkadang agak susah dalam pengoperasiannya. Masukan suara akan mempermudah penggunaan dan membuat sistem menjadi lebih interaktif dengan pengguna. Zakariyya, dkk (2015) dalam penelitiannya mebuktikan bahwa Speech Recognition adalah hal luar biasa yang mengagumkan. Ini adalah teknologi terkemuka untuk Human-Computer Interaction (HCI) dimasa yang akan datang. Speech Recognition adalah teknologi, dimana sistem memahami kata (dan artinya) yang diberikan melalui suara.

Akhmad, Andi dan Dodi (2016) telah melakukan penelitian tentang penggunaan suara untuk mengendalikan aplikasi. Hasil penelitian menyebutkan bahwa ada beberapa kelebihan saat menggunakan suara untuk input aplikasi diantaranya mudah untuk digunakan, penerapannya sederhana yang dapat membantu meningkatkan kenyamanan pengguna. Hal tersebut menjadi dasar penulis untuk mengembangkan sistem yang menggunakan masukan berupa suara dan layar sentuh agar sistem lebih mudah digunakan dan lebih interaktif.

Platform untuk sistem yang dibuat pada penelitian ini adalah android dikarenakan penggunaan yang mudah dan sudah dimiliki hampir setiap orang. Selain hal tersebut pemilihan platform android untuk digunakan dalam penelitian ini adalah karena fitur-fitur yang ada dalam android sangat mendukung untuk penggunaan inputan suara dan tidak memerlukan alat tambahan seperti Microphone atau headset.

Aplikasi Sistem Pakar Pendamping Perawatan Kesehatan Pribadi Berbasis Android "Co-Pad" (Companion Pad) dibuat untuk memberikan bantuan kepada masyarakat untuk mendiagnosa penyakit dari keluhan-keluhan yang dirasakan, dengan dua jenis input yaitu layar(touchscreen) dan suara(voice recognition). Aplikasi juga menyediakan informasi tambahan berupa keterangan, gejala, penyebab, dan cara pencegahan dari penyakit yang sering dirasakan oleh masyarakat. Tujuan utama pembuatan aplikasi ini adalah mengurangi kecenderungan masyarakat untuk langsung pergi kedokter apabila mengalami masalah kesehatan yang masih ringan.

\section{METODE}

Penulis menggunakan metode System Development Life Cycle dengan model waterfall untuk pengembangan aplikasi dalam penelitian yang dilakukan. Dengan teknik pencarian kesimpulan Decision Tree, yaitu merupakan teknik pencarian kesimpulan yang mempunyai aturan tertentu untuk dapat menentukan suatu kesimpulan akhir dari informasi yang telah diberikan. Proses SDLC metode Waterfall dapat dilihat pada gambar 1 . 


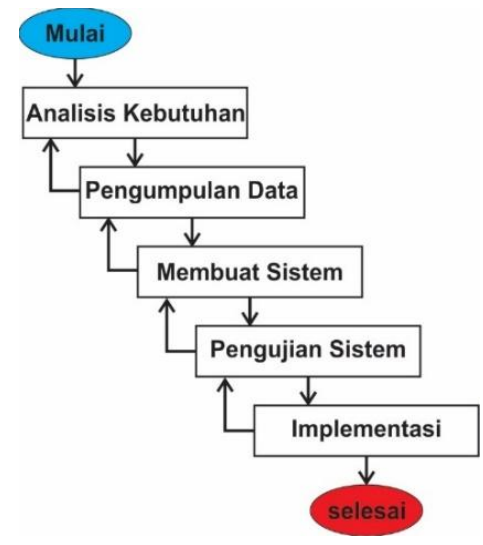

Gambar 1.SDLC Waterfall

\section{A. Menentukan Kebutuhan Sistem}

Pada penelitian ini software dan hardware yang digunakan untuk membuat sistem yang berbasis android adalah sebagai berikut.

Tabel 1. Daftar kebutuhan sistem

\begin{tabular}{|c|c|}
\hline Hardware & Software \\
\hline Laptop & a. Android \\
\hline X450L RAM 8GB & Studio \\
\hline OS Windows 10 & b. Corel Draw \\
\hline Smartphone VIVO & c. Database \\
\hline Y35 RAM 2GB OS & Mysql \\
\hline Android 5.0 & \\
\hline
\end{tabular}

\section{B. Menentukan Parameter Gejala/keluhan penyakit}

Pada tahap ini penulis mengumpulkan data dengan wawancara pada ahli yang sudah sering menangani masyarakat, sehingga sangat paham tentang penyakit apa saja yang sering diderita masayarakat. Dengan melakukan hal tersebut diperoleh data gejala-gejala/keluhan-keluhan yang sering dirasakan oleh masyarakat. Daftar gejala ditampilkan pada tabel 2 .
Tabel 2. Daftar Gejala/keluhan

\begin{tabular}{|c|c|}
\hline Id & Nama Gejala/Keluhan \\
\hline G01 & demam \\
\hline G02 & mual \\
\hline G03 & muntah \\
\hline G04 & $\begin{array}{l}\text { buang air besar lebih dari } 3 \text { kali } \\
\text { sehari }\end{array}$ \\
\hline G05 & terasa nyeri diseluruh bagian perut \\
\hline G06 & bentuk Feses cair \\
\hline G07 & Dehidrasi \\
\hline G08 & gatal \\
\hline G09 & pusing \\
\hline G10 & ruam berair \\
\hline G11 & ruam kemerahan pada kulit \\
\hline G12 & $\begin{array}{l}\text { Benjolan berwarna merah } \\
\text { dikelopak mata }\end{array}$ \\
\hline G13 & gaya berjalan berubah. \\
\hline G14 & $\begin{array}{l}\text { kaku dan nyeri sesudah istirahat } \\
\text { lama biasanya pagi hariatau } \\
\text { setelah bangun tidur, kurang dari } \\
30 \text { menit. }\end{array}$ \\
\hline G15 & keluar keringat dingin \\
\hline G16 & kepala terasa berputar \\
\hline G17 & kepala terasa ringan \\
\hline G18 & $\begin{array}{l}\text { kepala terasa terapung dan } \\
\text { terayun }\end{array}$ \\
\hline G19 & kesadaran menurun \\
\hline G20 & kulit tampak keriput \\
\hline $\mathrm{G} 21$ & kulit terasa panas \\
\hline $\mathrm{G} 22$ & lemah \\
\hline $\mathrm{G} 23$ & mata cekung \\
\hline $\mathrm{G} 24$ & $\begin{array}{l}\text { Merasa ada sesuatu yang } \\
\text { mengganjal dikelopak mata yang } \\
\text { bertambah sakit bila ditekan atau } \\
\text { menunduk }\end{array}$ \\
\hline $\mathrm{G} 25$ & Mulut dan bibir kering \\
\hline $\mathrm{G} 26$ & nyeri di perut bagian atas(ulu hati) \\
\hline $\mathrm{G} 27$ & nyeri dibagian kepala \\
\hline G28 & nyeri dikulit yang terdapat ruam \\
\hline G29 & Nyeri perut bagian bawah \\
\hline G30 & Nyeri Pinggang \\
\hline G31 & $\begin{array}{l}\text { nyeri tenggorok (terkadang } \\
\text { sampai telinga) }\end{array}$ \\
\hline G32 & Rasa gemeretak di sendi-sendi. \\
\hline G33 & ruam berupa bintik \\
\hline G34 & ruam kecil hingga besar \\
\hline
\end{tabular}




\begin{tabular}{|c|c|}
\hline G35 & $\begin{array}{l}\text { ruam pada tengkuk, lipatan siku, } \\
\text { lipatan lutut atau punggung kaki }\end{array}$ \\
\hline G36 & Sakit saat buang air kecil \\
\hline G37 & sakit saat menelan makanan \\
\hline G38 & $\begin{array}{l}\text { Sakit/linu sendi sesudah aktivitas } \\
\text { berlebihan( pada lutut, pinggul, } \\
\text { kaki, tulang belakang, tulang ekor } \\
\text { dan persendian yang lain) }\end{array}$ \\
\hline G39 & $\begin{array}{l}\text { sempoyongan waktu berjalan atau } \\
\text { berdiri }\end{array}$ \\
\hline G40 & sendi membengkak \\
\hline G41 & Sering buang air kecil \\
\hline G42 & sering mengantuk \\
\hline G43 & sesak nafas \\
\hline G44 & $\begin{array}{l}\text { tekanan darah menurun (cek } \\
\text { tekanan darah) }\end{array}$ \\
\hline G45 & $\begin{array}{l}\text { tenggorokan bagian kanan dan } \\
\text { kiri membengkak }\end{array}$ \\
\hline G46 & terasa asam dimulut \\
\hline G47 & terasa mudah kenyang \\
\hline G48 & terasa pahit dimulut \\
\hline G49 & Terasa panas saat buang air kecil \\
\hline G50 & $\begin{array}{l}\text { Timbul ruam berwarna lebih } \\
\text { gelap/terang daripada kulit } \\
\text { sekitarnya }\end{array}$ \\
\hline G51 & $\begin{array}{l}\text { Rasa Gatal terutama saat } \\
\text { berkeringat }\end{array}$ \\
\hline G52 & $\begin{array}{l}\text { Adanya dahak di saluran } \\
\text { pernafasan }\end{array}$ \\
\hline G53 & mengi (bunyi saat nafas) \\
\hline G54 & denyut nadi meningkat \\
\hline G55 & Sering bersendawa \\
\hline
\end{tabular}

\section{Menentukan Parameter Penyakit}

Pada tahap ini penulis mengumpulkan data dengan wawancara pada ahli yang sudah sering menangani masyarakat, sehingga sangat paham tentang penyakit apa saja yang sering diderita masayarakat. Dengan melakukan hal tersebut diperoleh data penyakit yang sering dirasakan oleh masyarakat.
Tabel 3. Daftar Penyakit

\begin{tabular}{|ll|}
\hline $\begin{array}{l}\text { Id Gejala } \\
\text { /Keluhan }\end{array}$ & \multicolumn{1}{c|}{ Nama Gejala/Keluhan } \\
\hline P01 & $\begin{array}{l}\text { Gangguan Pencernaan } \\
\text { (Syndroma Dyspepsia) }\end{array}$ \\
\hline P02 & $\begin{array}{l}\text { Radang Tenggorokan } \\
\text { (Faringitis/Tonsilitis) }\end{array}$ \\
\hline P03 & $\begin{array}{l}\text { Sakit Kepala } \\
\text { (Cephalgi/Headache) }\end{array}$ \\
\hline P04 & ISK (Infeksi Saluran Kemih) \\
\hline P05 & $\begin{array}{l}\text { Dermatomikosis (Penyakit } \\
\text { Kulit karena Jamur) }\end{array}$ \\
\hline P06 & $\begin{array}{l}\text { Osteoartritis (Sakit pada } \\
\text { Persendian) }\end{array}$ \\
\hline P07 & Dehidrasi (kekurangan cairan) \\
\hline P08 & Diare \\
\hline P09 & Diare akut \\
\hline P10 & Diare berkepanjangan \\
\hline P11 & Diare Kronik \\
\hline P12 & Nyeri Haid (Dismenore) \\
\hline P13 & Vertigo \\
\hline P14 & Hordeolum (Iritasi Mata) \\
\hline P15 & Dermatitis Atopik \\
\hline P16 & Dermatitis Kontak Iritan \\
\hline P17 & Dermatitis Kontak Alergi \\
\hline P18 & Influenza \\
\hline p19 & Batuk-batuk \\
\hline P20 & Asma \\
\hline P21 & Sakit Maag \\
\hline P22 & Migrain \\
\hline
\end{tabular}

\section{Menentukan Aturan/Rule}

Sesuai data yang diperoleh dari sumber dapat dibuat aturan yang dapat diproses menggunanakan metode Decision Tree untuk mengetahui hasil akhir. Berikut aturan/rule yang dapat dibuat dari data yang telah diperoleh: 
Tabel 4. Daftar Aturan/rule

\begin{tabular}{|ll|}
\hline No. & Aturan/Rule \\
\hline R01 & $\begin{array}{l}\text { IF G02 \& G03 \& G09 \& G26 \& G46 \& } \\
\text { G47 \& G48 THEN P01 }\end{array}$ \\
\hline R02 & IF G01 \& G31 \& G37 THEN P02 \\
\hline R03 & IF G02 \& G27 THEN P03 \\
\hline R04 & $\begin{array}{l}\text { IF G01 \& G29 \& G30 \& G36 \& G41 \& } \\
\text { G49 THEN P04 }\end{array}$ \\
\hline R05 & IF G08 \& G50 \& G51 THEN P05 \\
\hline R06 & $\begin{array}{l}\text { IF G13 \& G14 \& G32 \& G38 \& G40 } \\
\text { THEN P06 }\end{array}$ \\
\hline R07 & $\begin{array}{l}\text { IF G09 \& G19 \& G20 \& G22 \& G23 \& } \\
\text { G25 \& G42 \& G43 \& G44 THEN P07 }\end{array}$ \\
\hline R08 & $\begin{array}{l}\text { IF G01 \& G02 \& G03 \& G04 \& G05 \& } \\
\text { G06 \& G07 THEN P08 }\end{array}$ \\
\hline R09 & $\begin{array}{l}\text { IF G01 \& G02 \& G03 \& G04 \& G05 \& } \\
\text { G06 \& G07 THEN P09 }\end{array}$ \\
\hline R10 & $\begin{array}{l}\text { IF G01 \& G02 \& G03 \& G04 \& G05 \& } \\
\text { G06 \& G07 THEN P10 }\end{array}$ \\
\hline R11 & $\begin{array}{l}\text { IF G01 \& G02 \& G03 \& G04 \& G05 \& } \\
\text { G06 \& G07 THEN P11 }\end{array}$ \\
\hline R13 & $\begin{array}{l}\text { IF G02 \& G09 \& G15 \& G16 \& G17 \& } \\
\text { G18 \& G39 THEN P13 }\end{array}$ \\
\hline R14 & IF G12 \& G24 THEN P14 \\
\hline R15 & $\begin{array}{l}\text { IF G08 \& G10 \& G11 \& G35 THEN } \\
\text { P15 }\end{array}$ \\
\hline R16 & $\begin{array}{l}\text { IF G08 \& G10 \& G11 \& G21 \& G28 \& } \\
\text { G34 THEN P16 }\end{array}$ \\
\hline R17 & IF G10 \& G11 \& G33 THEN P17 \\
\hline R19 & IF G01 \& G31 \& G52 THEN P19 \\
\hline R20 & $\begin{array}{l}\text { IF G01 \& G31 \& G53 \& G43 \& G54 } \\
\text { THEN P20 }\end{array}$ \\
\hline R21 & $\begin{array}{l}\text { IF G02 \& G03 \& G09 \& G26 \& G47 \& } \\
\text { G55 THEN P21 }\end{array}$ \\
\hline
\end{tabular}

\section{E. Desain Sistem}

Tahap ini dimaksudkan untuk menggambarkan sistem yang dibuat

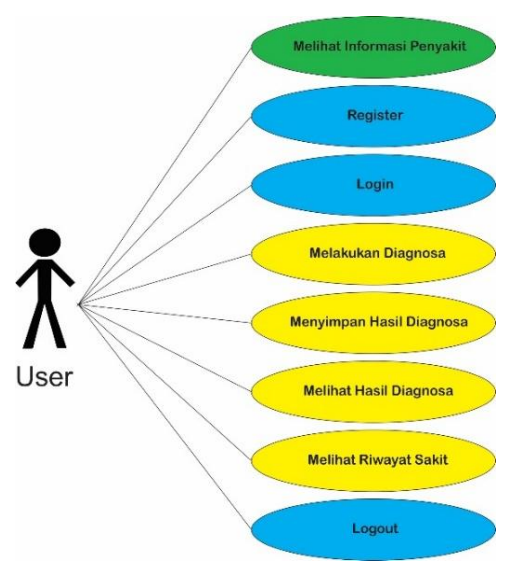

Gambar 2. Use-case Diagram

Gambar 2 menjelaskan peran user dalam aplikasi. User memiliki hak akses untuk register, login, melakukan diagnosa, menyimpan hasil diagnosa serta melihat hasil diagnose dan logout.

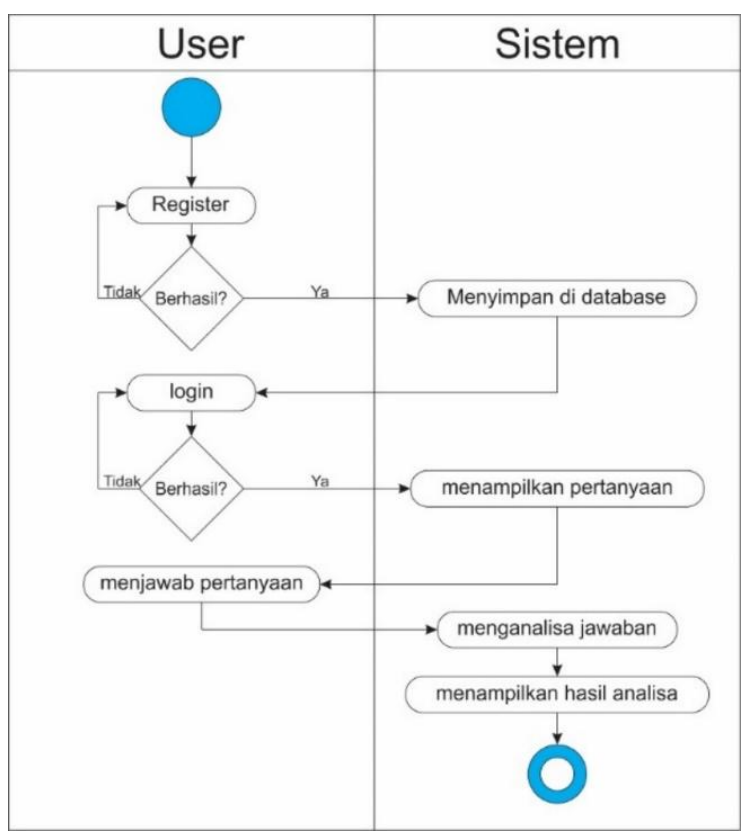

Gambar 3. Activity Diagram

Gambar 3 menjelaskan bagaimana aktivitas yang dilakukan user dan sistem saat menjalankan aplikasi. Saat user pertama kali menggunakan sistem akan diminta untuk register agar dapat login kedalam sistem. Apabila proses register selesai dan user sudah bisa login kedalam sistem maka sistem akan menampilkan pertanyaan yang harus dijawab oleh user sesuai dengan gejala/keluhan yang dirasakan. Sistem akan menganalisa jawaban 
tersebut untuk kemudian ditampilkan kepada user.

\section{HASIL DAN PEMBAHASAN}

Bagian ini akan dijelaskan tentang implementasi aplikasi serta pengujian Aplikasi Sistem Pakar Pendamping Perawatan Kesehatan Pribadi Berbasis Android "Co-Pad" (Companion Pad).

\section{A. Implementasi}

\section{Splashscreen dan Login}

Splashscreen adalah halaman yang ditampilkan pertama kali oleh sistem, pada halaman ini terjadi proses inisialisasi oleh sistem. Halaman ini adalah bagian aplikasi yang berperan untuk mempersiapkan semua komponen sebelum aplikasi berjalan. Beberapa hal yang dilakukan adalah, memeriksa koneksi ijin internet, memeriksa ijin perekam suara, serta memeriksa komponen-komponen lain dalam sistem. Halaman ini ditampilkan selama sekitar 3 detik, berisi nama dan logo aplikasi Companion Pad. Setelah itu akan mengarah ke halaman login untuk masuk ke dalam aplikasi. Tampilan halaman Splashscreen dan login ditampilkan pada gambar 4.

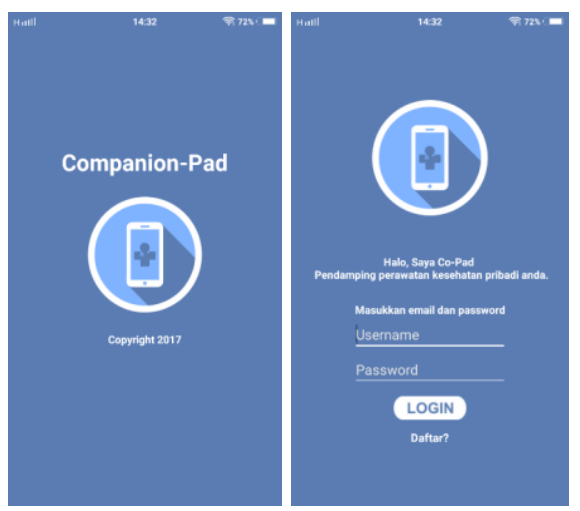

Gambar 4. Halaman Splashscreen dan login

\section{Menu Utama/Halaman Utama}

Halaman utama merupakan pusat dari segala proses aplikasi. Halaman utama berisi beberapa komponen diantaranya tombol untuk memulai diagnosa yang berada dibagian bawah layar, tombol menu dibagian pojok kiri atas layar serta tulisan petunjuk perintah suara pada tengah layar aplikasi. Tampilan halaman utama dan menu ditampilkan pada gambar 5 .

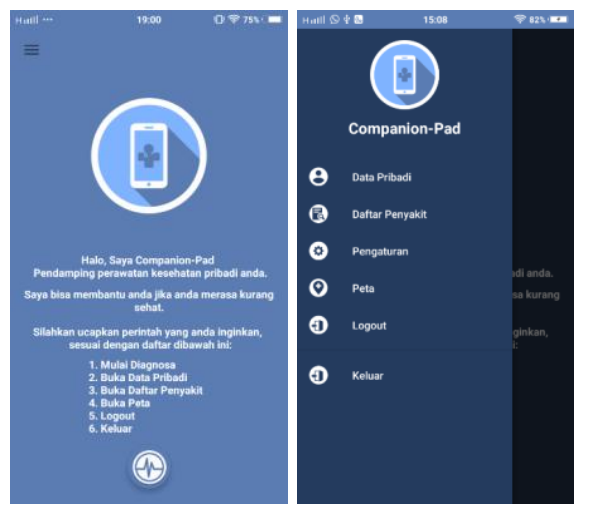

Gambar 5. Halaman Utama dan Menu

\section{Diagnosa Penyakit (Fitur Utama)}

Untuk memulai diagnosa penyakit, pengguna hanya perlu menekan tombol mulai diagnosa atau mengucapkan "mulai diagnosa" pada halaman utama. Selanjutnya akan ditampilkan beberapa gejala yang harus dijawab oleh pengguna, pengguna dapat menjawab dengan menekan tombol ceklist apabila merasakan gejala yang ditanyakan atau silang apabila tidak merasakannya. Bisa juga menjawab dengan berkata "ya" atau "tidak" apabila mode masukan suara aktif. Fitur ini diakhiri dengan menampilkan keterangan, gejala dan cara menanganani penyakit hasil diagnosa. Tampilan-tampilan Fitur Diagnosa ditampilkan pada gambar 6.

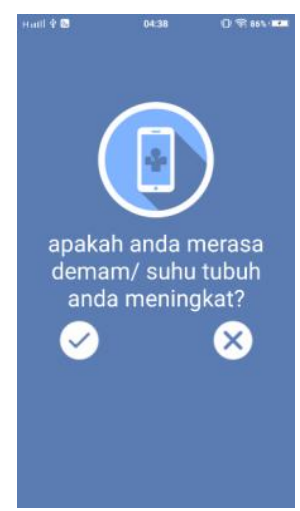



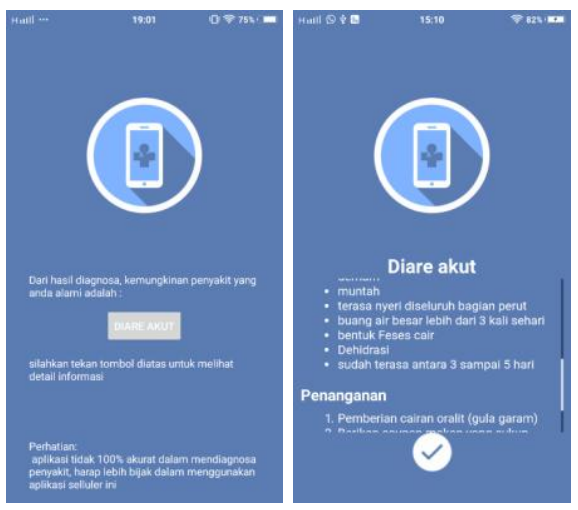

Gambar 6. Fitur Diagnosa

\section{Menu Data Pribadi dan Riwayat Diagnosa Sistem}

Menu ini akan menampilkan halaman yang berisi data diri pengguna berupa nama dan tanggal lahir sesuai yang dimasukkan pengguna pada saat mendaftar aplikasi. Selain itu aplikasi juga akan menampilkan daftar riwayat diagnosa pengguna pada aplikasi Companion Pad, serta keterangan diagnosa tersebut. Tampilan menu data pribadi dan riwayat penyakit ditampilkan pada gambar 7 .

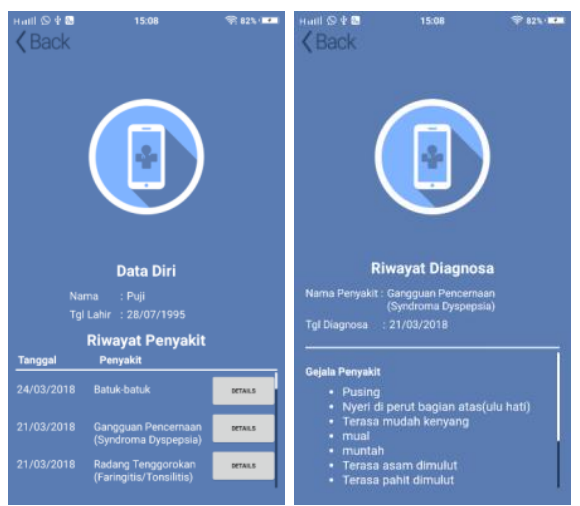

Gambar 7. Tampilan menu Data Pribadi

\section{Menu Daftar Penyakit}

Menu ini akan menampilkan halaman yang berisi daftar penyakit yang tersedia dalam aplikasi penyakit yang ditampilkan hanya yang dapat ditangani sendiri oleh pengguna, untuk penyakit berat tidak terdapat dalam daftar ini. Tampilan menu daftar penyakit ditampilkan pada gambar 8 .

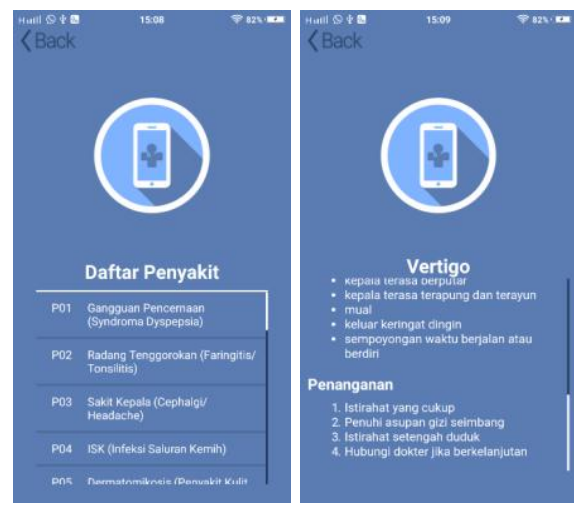

Gambar 8. Tampilan Menu Daftar Penyakit

\section{Menu Peta}

Menu ini akan menampilkan peta. Peta yang ditampilkan berisi fitur untuk mencari dokter, rumah sakit serta apotek disekitar pengguna. Tampilan menu Peta ditampilkan pada gambar 9.

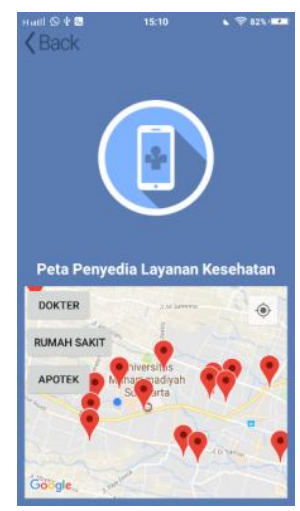

Gambar 9. Tampilan Menu Peta

Selain fitur-fitur diatas ada beberapa menu lain yang dapat digunakan yaitu, pengaturan untuk mengaktifkan/menonaktifkan mode masukan suara. Logout untuk keluar dari akun yang sedang aktif. Menu keluar untuk keluar dari aplikasi. Semua fitur yang terdapat dalam aplikasi telah diuji coba dan dapat berjalan dengan baik.

\section{B. Pengujian}

Aplikasi diuji dengan beberapa pengujian, diantaranya pengujian blackbox, pengujian validasi dan pengujian user acceptance.

\section{Pengujian Blackbox}

Pengujian dilakukan pada semua fitur aplikasi Companion Pad, hasil pengujian menunjukkan bahwa semua fitur pada aplikasi dapat berjalan dengan baik. Pengujian fitur masukan suara 
menunjukkan bahwa fitur berjalan dengan sangat baik, karena dapat menerjemahkan suara menjadi teks dengan sangat akurat.

\section{Validasi Aturan/Rules}

Pengujian validitas data didalam aplikasi dilakukan untuk memastikan bahwa data yang ada dalam aplikasi sudah valid. Setelah dilakukan validasi aplikasi oleh dokter dari 19 aturan yang ada bisa dibuat menjadi algoritma dengan kombinasi gejala sesuai dengan arahan pakar/dokter. Hasil validasi menunjukkan bahwa hasil diagnosa sistem sesuai dengan hasil diagnosa pakar.

\section{User Acceptance Test}

Pengujian user acceptance test dilakukan dengan cara menyebar kuisioner kepada 30 responden. Data yang terkumpul dihitung persentasenya dengan persamaan (1).

$$
\boldsymbol{P}=\frac{s \times 100 \%}{S \max }
$$

Dalam persamaan (1), S adalah skor untuk masing-masing pernyataan yang dihitung dengan persamaan (2),

$\mathbf{S} \quad($ Skor $)=\Sigma$ (Jumlah reponden yang menjawab×bobot jawaban) (2)

Sedangkan Smax adalah nilai tertinggi yang dihitung dengan persamaan (3),

Smax (Nilai tertinggi $)=5 \times$ Jumlah responden

$$
\text { (3) }
$$

Hasil perhitungan user acceptance test disajikan pada table 5, dan diilustrasikan dengan grafik pada gambar 10 .

Tabel 5. Hasil Pengujian User Acceptance

\begin{tabular}{|c|c|c|c|c|c|c|c|}
\hline No. & Kode & $\mathbf{S}$ & $\mathbf{S}$ & $\mathbf{T}$ & $\mathbf{S T}$ & $\begin{array}{c}\text { Jumla } \\
\text { h Skor } \\
\text { (S) }\end{array}$ & $\begin{array}{c}\text { Persenta } \\
\text { se }\end{array}$ \\
\hline $\mathbf{1}$ & P01 & 11 & 18 & 1 & 0 & 100 & $83,3 \%$ \\
\hline $\mathbf{2}$ & P02 & 7 & 18 & 5 & 0 & 92 & $76,6 \%$ \\
\hline $\mathbf{3}$ & P03 & 3 & 26 & 1 & 0 & 92 & $76,6 \%$ \\
\hline $\mathbf{4}$ & P04 & 12 & 16 & 2 & 0 & 106 & $88,3 \%$ \\
\hline $\mathbf{5}$ & P05 & 15 & 15 & 0 & 0 & 105 & $87,5 \%$ \\
\hline 6 & P06 & 5 & 19 & 6 & 0 & 99 & $82,5 \%$ \\
\hline 7 & P07 & 11 & 18 & 1 & 0 & 100 & $83,3 \%$ \\
\hline
\end{tabular}

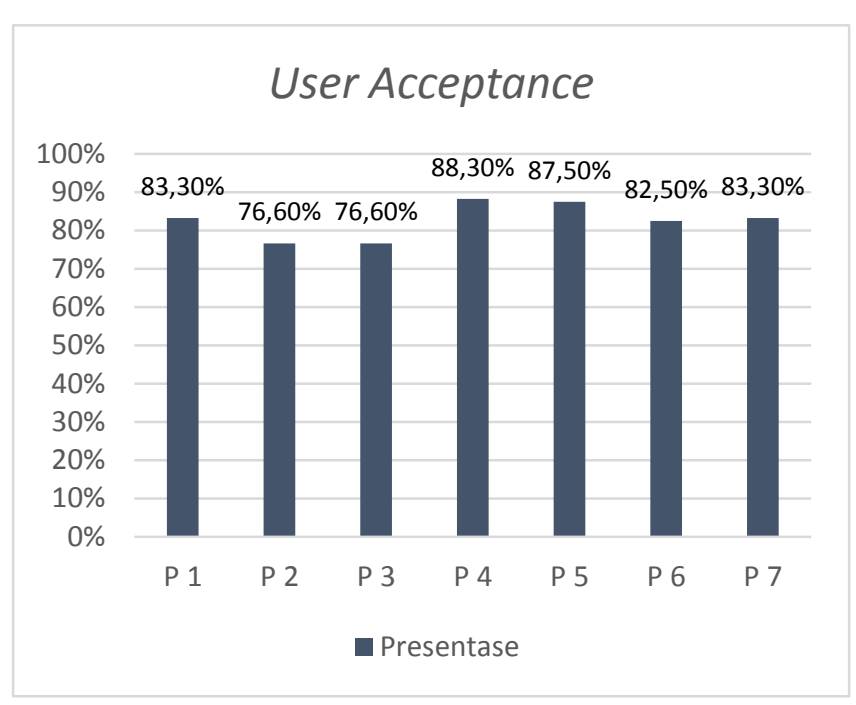

Gambar 10. Grafik user acceptance

Berdasarkan pada tabel 6 dan gambar grafik 10 dapat dilihat bahwa skor tertinggi adalah $88,3 \%$ pada pernyataan 4 sedangkan skor terendah adalah $76,6 \%$ pada pernyataan 2 dan 3. Rata-rata skor dari hasil pengujian user acceptance adalah $82,6 \%$ maka dapat disimpulkan bahwa sistem dapat diterima dengan sangat baik oleh user.

\section{PENUTUP}

Berdasarkan pada hasil dan pembahasan penelitian ini, dapat diambil kesimpulan bahwa sistem bekerja dengan cukup baik, meskipun terkadang masih ada bug yang terkadang muncul dikarenakan berbagai hal. Sistem mampu mendiagnosa, menampilkan data diri dan riwayat diagnosa, menampilkan daftar penyakit serta dapat menampilkan peta penyedia layanan kesehatan disekitar pengguna. Fitur masukan suara dapat dengan akurat menerjemahkan suara menjadi teks. Berdasarkan pengujian validasi Aturan/rule, aplikasi mampu memberikan hasil diagnosa yang sesuai dengan hasil diagnosa pakar, sehingga pengguna dapat mengetahui gejalagejala penyakit tanpa harus kedokter karena validitas sistem sudah teruji, jika penyakitnya masih tergolong ringan dan dapat ditangani sendiri. Aplikasi ini termasuk sistem pakar yang baik karena dapat memberikan hasil yang baik dan dapat diterima oleh masyarakat 
dengan baik, dibuktikan dengan presentase user acceptance mencapai 82,6\%.

Fitur masukan suara sangat membantu karena lebih mudah digunakan dan dengan panduan suara pengguna merasa lebih mudah memahami, dan lebih ter-arahkan daripada hanya sekedar membaca tulisan. Dibalik keunggulan aplikasi Companion Pad pasti ada beberapa kekurangan yang mungkin belum pengembang temui. Saran penulis kedepannya menambahkan beberapa referensi penyakit yang dapat di-diagnosa oleh pengguna khususnya masyarakat secara umum.

\section{DAFTAR PUSTAKA}

[1] Abdullahi, Z.H., Muhammad, N.A., Kazaure, J.S., Amuda F.A. (2015) Mobile Robot Voice Recognition in Control Movements. International Journal of Computer Science and Electronics Engineering (IJCSEE) Volume 3, Issue 1 (2015) ISSN: 2320-4028

[2] Bria, Y.P., \& Takung, E.A.S. (2015). Pengembangan Sistem Pakar Diagnosa Penyakit Tuberculosis dan Demam Berdarah Berbasis Web Menggunakan
Metode Certainly Factor, Seminar Nasional Teknologi dan Komunikasi, ISSN: 2089-9815

[3] Dani A.W., Adriansyah, A. \& Hermawan D. (2016). Perancangan Aplikasi Voice Command Recognition Berbasis Android dan Arduino UNO. Jakarta: Jurnal Teknologi Elektro, Universitas Mercu Buana. Vol.07, No.01. ISSN: 2086-9479

[4] Supriyono, H., Sujalwo, Sulistyawati, T. \& Trikuncahyo, A.R. (2015). Sistem Pakar Berbasis Logika Kabur untuk Penentuan Penerima Beasiswa. Surakarta: Jurnal Emitor. Vol. 15, No. 01. ISSN: 1411-8890

[5] Oluwafemi, Ayangbekun, \& Jimoh Ibrahim A. 2015. Expert System for diagnosis Neurodegenerative Diseases. International Journal of Computer and Information Technology. Vol. 04, Issue 04

[6] Kementerian Kesehatan Republik Indonesia. 2017. Profil Kesehatan Indonesia Tahun 2016. Jakarta: Kementerian Kesehatan Republik Indonesia. ISBN 978-602-416-253-5 